\title{
Brain-computer interfaces for communication with nonresponsive patients
}

\author{
Citation for published version (APA):
}

Naci, L., Monti, M. M., Cruse, D., Kübler, A., Sorger, B., Goebel, R., Kotchoubey, B., \& Owen, A. M. (2012). Brain-computer interfaces for communication with nonresponsive patients. Annals of Neurology, 72(3), 312-323. https://doi.org/10.1002/ana.23656

Document status and date:

Published: 01/01/2012

DOI:

10.1002/ana.23656

Document Version:

Publisher's PDF, also known as Version of record

Document license:
Taverne

\section{Please check the document version of this publication:}

- A submitted manuscript is the version of the article upon submission and before peer-review. There can be important differences between the submitted version and the official published version of record.

People interested in the research are advised to contact the author for the final version of the publication, or visit the DOI to the publisher's website.

- The final author version and the galley proof are versions of the publication after peer review.

- The final published version features the final layout of the paper including the volume, issue and page numbers.

Link to publication

\footnotetext{
General rights rights.

- You may freely distribute the URL identifying the publication in the public portal. please follow below link for the End User Agreement:

www.umlib.nl/taverne-license

Take down policy

If you believe that this document breaches copyright please contact us at:

repository@maastrichtuniversity.nl

providing details and we will investigate your claim.
}

Copyright and moral rights for the publications made accessible in the public portal are retained by the authors and/or other copyright owners and it is a condition of accessing publications that users recognise and abide by the legal requirements associated with these

- Users may download and print one copy of any publication from the public portal for the purpose of private study or research.

- You may not further distribute the material or use it for any profit-making activity or commercial gain

If the publication is distributed under the terms of Article $25 \mathrm{fa}$ of the Dutch Copyright Act, indicated by the "Taverne" license above, 


\title{
Brain-Computer Interfaces for Communication with Nonresponsive Patients
}

\author{
Lorina Naci, PhD, ${ }^{1}$ Martin M. Monti, $\mathrm{PhD}^{2}$ Damian Cruse, $\mathrm{PhD},{ }^{1}$ Andrea Kübler, $\mathrm{PhD},{ }^{3}$ \\ Bettina Sorger, $\mathrm{PhD}^{4}$ Rainer Goebel, $\mathrm{PhD}^{4}{ }^{4}$ Boris Kotchoubey, $\mathrm{PhD}^{5}$ \\ and Adrian M. Owen, $\mathrm{PhD}^{1}$
}

\begin{abstract}
A substantial number of patients who survive severe brain injury progress to a nonresponsive state of wakeful unawareness, referred to as a vegetative state (VS). They appear to be awake, but show no signs of awareness of themselves, or of their environment in repeated clinical examinations. However, recent neuroimaging research demonstrates that some VS patients can respond to commands by willfully modulating their brain activity according to instruction. Brain-computer interfaces ( $\mathrm{BCls}$ ) may allow such patients to circumvent the barriers imposed by their behavioral limitations and communicate with the outside world. However, although such devices would undoubtedly improve the quality of life for some patients and their families, developing $\mathrm{BCl}$ systems for behaviorally nonresponsive patients presents substantial technical and clinical challenges. Here we review the state of the art of $\mathrm{BCl}$ research across noninvasive neuroimaging technologies, and propose how such systems should be developed further to provide fully fledged communication systems for behaviorally nonresponsive populations.
\end{abstract}

ANN NEUROL 2012;72:312-323

$\mathrm{P}$ atients with serious brain injury may be rendered behaviorally nonresponsive for a variety of reasons (Fig 1, Table 1). The locked-in syndrome (LIS) describes an individual who, as a result of acute injury to the brainstem, in particular to the anterior pons, has (almost) entirely lost the ability to produce motor actions. Following injury, it is often possible for clinicians to confirm the presence of preserved sensory, cognitive, and emotional abilities in these patients on the basis of small but reproducible movements. ${ }^{1,2}$ In the acute phase of LIS, consciousness is frequently impaired, ${ }^{3,4}$ especially if there is brain swelling beyond the areas immediately affected by the infarct, or where there are additional extrapontine (eg, thalamic) infarcts. ${ }^{5}$ However, this impairment rarely attains the level of complete or nearly complete loss of awareness, and usually disappears with the passage into the chronic phase. The most severe LIS patients, labeled as completely locked-in (CLIS), are entirely unable to perform any voluntary movements, including minor motor responses such as eye movements. ${ }^{6}$ Such a state is sometimes observed also in patients in the advanced stages of amyotrophic lateral sclerosis (ALS), ${ }^{7,8}$ and although the presence of consciousness in these patients is rarely questioned, progressive cognitive disturbances do occur. $^{9-11}$ In the latest stages of the disease, these disturbances may result in disorders of consciousness (DOC).

Unlike LIS patients, patients in the vegetative state (VS) are clinically diagnosed on the basis of their behavioral profile, particularly signs of wakefulness (ie, periodic eye opening and closing) in the absence of signs of awareness of themselves, or of the environment, rather than on the basis of a particular neural pathology. ${ }^{12}$ Although the distribution of etiologies and pathological features ${ }^{13}$ of the VS has been studied, ${ }^{14}$ their variance among the demographic distribution of these patients, and others who are in a minimally conscious state

View this article online at wileyonlinelibrary.com. DOI: 10.1002/ana.23656

Received Feb 21, 2012, and in revised form Apr 25, 2012. Accepted for publication May 21, 2012

Address correspondence to Dr Naci, The Brain and Mind Institute, Department of Psychology, Western University, London, Ontario, N6A 5B7, Canada. E-mail: lorina.clare@gmail.com

From the ${ }^{1}$ The Brain and Mind Institute, Department of Psychology, Western University, London, Ontario, Canada; ${ }^{2}$ Department of Psychology, University of California at Los Angeles, Los Angeles, CA; ${ }^{3}$ Department of Psychology I, University of Würzburg, Würzburg, Germany; ${ }^{4}$ Department of Cognitive

Neuroscience, Faculty of Psychology and Neuroscience, Maastricht University, Maastricht, the Netherlands; and ${ }^{5}$ Institute of Medical Psychology and Behavioral Neurobiology, Eberhard-Karls-University, Tübingen, Germany. 
Non-responsive patients with disorders of consciousness

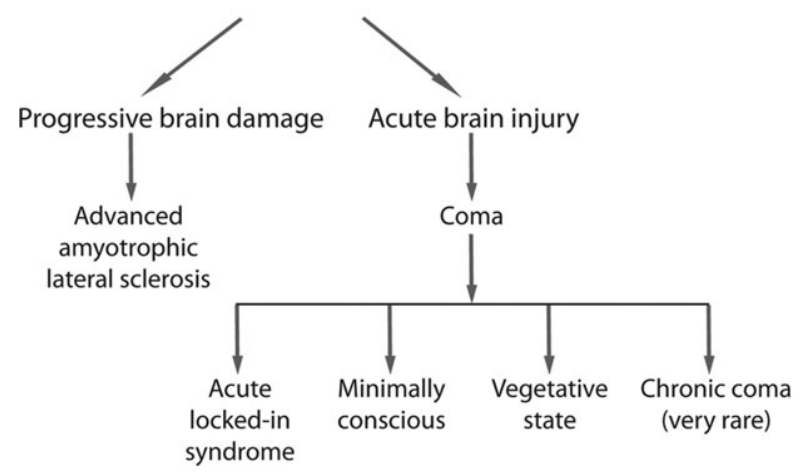

FIGURE 1: Flow chart of patient populations that exhibit nonresponsive conditions. Some patients suffering from advanced stages of progressive brain damage, such as amyotrophic lateral sclerosis, can become nonresponsive. The presence of consciousness is rarely questioned in these patients. Patients suffering acute brain injury may fall into coma and develop a variety of clinical states differing in awareness and responsivity, from none to very limited. In rare cases, they may evolve to chronic coma, which is characterized by a permanent lack of wakefulness, with no spontaneous eye opening, even to intense stimulation, and lack of awareness. Other patients may progress to the vegetative state, where they display some wakefulness, including eye opening and stimulus-induced arousal, but no awareness of themselves or of their environment. Minimally conscious patients demonstrate inconsistent, but reproducible signs of awareness. Locked-in patients, except for those completely locked-in, often exhibit signs of awareness through small, but reproducible movements. Image adapted from Laureys S, Owen AM, Schiff ND. Brain function in coma, vegetative state, and related disorders. Lancet Neurol 2004;3:537-546.

(MCS), or exhibit limited signs of awareness, is not known. Some patients may remain indefinitely in a VS. (See Laureys et $\mathrm{al}^{15}$ for a discussion of a newly introduced term, unresponsive wakefulness syndrome, which aims to steer away from the negative connotations that the label VS may attract.) Other patients, as they recover their ability to demonstrate inconsistent but reproducible signs of awareness, are said to progress to an MCS. ${ }^{16}$ The clinical assessment of these patients is particularly difficult because of its reliance on the subjective interpretation of inconsistent behaviors, which are often limited by motor constraints. ${ }^{17,18}$ It is well established that misdiagnosis occurs frequently in this patient group, with up to $40 \%$ of patients being diagnosed as VS, when they are in fact (minimally) aware. ${ }^{19-21}$

Although a clinical diagnosis of VS implies lack of consciousness and cognition, this is not necessarily always the case. Electroencephalographic (EEG) and functional magnetic resonance imaging (fMRI) studies have shown that appropriate brain responses to stimuli of varying complexity can be preserved in some patients. These include basic sensory functions ${ }^{22,23}$ and higher cognitive processes, such as emotional ${ }^{24,25}$ and semantic processing. ${ }^{26-30}$ Some patients, who behaviorally appear to be entirely vegetative, are even able to follow commands by modulating their brain activity, thereby indicating that they are consciously aware despite their clinical diagnosis. ${ }^{31-33}$

If functional neuroimaging can be employed to allow some VS patients to demonstrate that they have preserved awareness, it may also be possible to use the same technologies as a means for such patients to communicate with the outside world. In this review, we will consider the current state of the art of so-called braincomputer interfaces (BCIs) that rely on noninvasive functional neuroimaging, and discuss their potential for application in nonresponsive patients with disorders of consciousness, including VS and MCS patients. We focus

\begin{tabular}{|c|c|}
\hline Disorder & Description \\
\hline Coma & $\begin{array}{l}\text { There are no signs of wakefulness-no spontaneous eye opening, even } \\
\text { to intense stimulation-and no signs of awareness. Usually it is transient: } \\
\text { a few days or weeks. In rare cases, it is chronic. }\end{array}$ \\
\hline Vegetative state & $\begin{array}{l}\text { There are signs of wakefulness, including eye opening and stimulus-induced } \\
\text { arousal, but no signs of awareness of oneself or of the environment. The } \\
\text { state is considered permanent } 1 \text { year after a traumatic brain injury, or } \\
3 \text { months after brain damage from lack of oxygen. }\end{array}$ \\
\hline Minimally conscious state & $\begin{array}{l}\text { There are signs of wakefulness and inconsistent, but reproducible signs of awareness, } \\
\text { including sustained visual pursuit, command following, and intelligible verbalization. } \\
\text { It may be chronic or permanent, although no time intervals have been defined. }\end{array}$ \\
\hline Locked-in state & $\begin{array}{l}\text { Patients are usually aware, but unable to move or speak, and unless completely } \\
\text { locked, in they may communicate via small eye movements. In the acute phase, } \\
\text { awareness may be impaired. }\end{array}$ \\
\hline
\end{tabular}




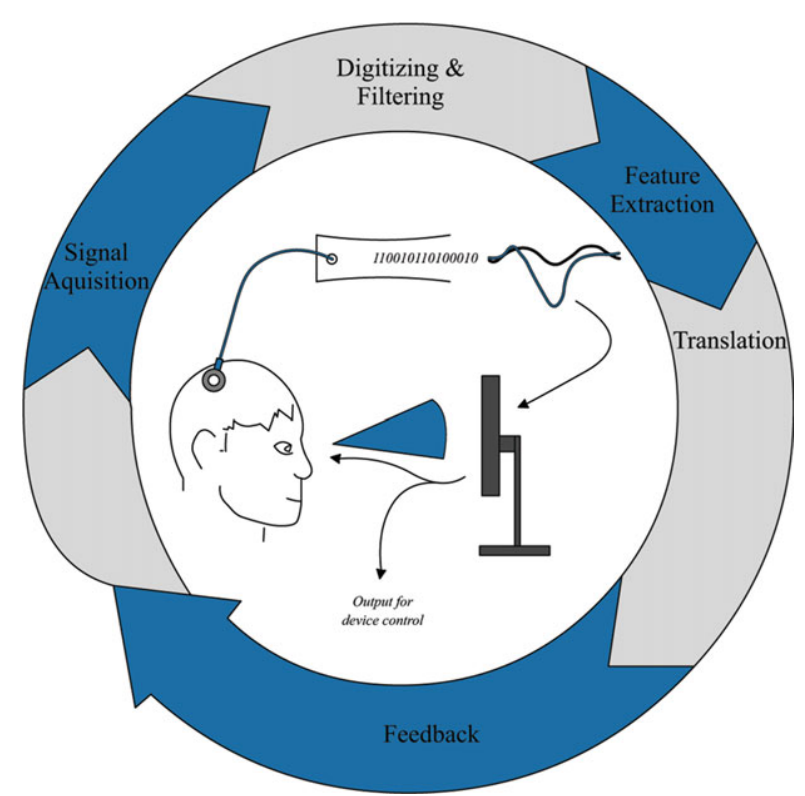

FIGURE 2: Schematic representation of a brain-computer interface $(\mathrm{BCl})$ system. The $\mathrm{BCl}$ cycle starts with the user engaging in a task, in the presence or absence or sensory stimulation. The resulting brain signal wave is preprocessed and analyzed for specific features that signal the user's intent, and translated into a command, which brings about a state change of the $\mathrm{BCl}$ system. This is fed back to the user, for example, through a visual display. This cycle can be repeated iteratively to achieve online communication between the operator and $\mathrm{BCl}$ user (courtesy of Andrea Kübler).

mainly on experimental paradigms that would be accessible to VS patients, as these patients are the most challenging to reach, because the least is known about any residual cognition. Therefore, BCI paradigms for VS patients must be the most robust, and the least dependent on prior assumptions about a patient's cognitive abilities. The decision to focus on this group was based on the high proportion of such patients (40\%) whose awareness is not detected through bedside examinations. Paradigms that are applicable to VS patients are also generally applicable more widely to patients with evident signs of spared cognition (eg, MCS). Undoubtedly, similarly to VS, MCS patients stand to benefit greatly from the development of BCI devices that might improve on the extremely limited and inconsistent communication achieved through their gestural and verbal output.

\section{$\mathrm{BCls}$}

Typically, BCI applications with (behaviorally) responsive participants involve analysis and classification of brain responses, produced either voluntarily, or in response to sensory stimulation, to infer a desired command that reflects the user's intention. The executed command brings about a state change of the BCI system that is communicated to the BCI user, for example, through a visual display. ${ }^{5,34}$ This cycle can be repeated iteratively until there is bidirectional feedback, or online communication between the user and the operator (Fig 2). ${ }^{34}$ Such an advanced BCI system involves reading and interpreting the user's intention in real time to produce physical outcomes/changes in the system, which can inform the user's subsequent response.

For conscious participants, the BCI user's intent is clear-for example, to regulate one's own brain activity, such as that which produces the sensation of chronic pain, via neurofeedback. ${ }^{35} \mathrm{~A}$ major hurdle in communicating with behaviorally nonresponsive patients is the lack of a priori knowledge about their level of conscious awareness, cognitive capacities, and even their communicative intent. Moreover, the level of arousal, awareness, and more generally, cognition varies dramatically between patients who are truly in a VS and those who are (minimally) aware, but have been misdiagnosed as VS. Thus, to maximize the chances that any given patient will be able to respond, a BCI system for DOC patients must be as robust to this variation, and as straightforward to use, as possible.

Another significant challenge in the development of $\mathrm{BCIs}$ for DOC patients is the limited sensory processing that these patients are likely to have. ${ }^{20}$ The majority of BCI techniques, which have been developed for conscious participants, rely on visual stimulation and feedback. $^{36-40}$ However, vision is among the most affected senses in DOC patients. ${ }^{20,41}$ By definition, VS patients lack the ability to fixate on or pursue objects in their visual field, ${ }^{12}$ which results in highly impaired visual processing. This precludes the use of visually based BCI systems in this group, and moreover the modification of such systems for use in other modalities (eg, auditory) is not trivial. ${ }^{42,43}$

Below, we review BCI research in 3 noninvasive neuroimaging technologies, fMRI, EEG, and functional near-infrared spectroscopy (fNIRS), all of which may be applicable to varying degrees in nonresponsive patients (Table 2). Invasive technologies, such as electrocorticography, single microelectrodes, or microelectrode arrays involve implantation of electrodes in the cortex, and therefore provide superior signal-to-noise ratio and better detection of high-frequency oscillatory activity ${ }^{44-47}$ than noninvasive technologies. A proof of principle study used invasive electrodes in a BCI application for patients with limited behavioral response (eg, locked-in). ${ }^{48}$ However, invasive technologies are of limited relevance to patients who are the main focus of this article for several reasons. Electrode implantation is often a corollary of a surgical procedure in the course of a patient's treatment, and 


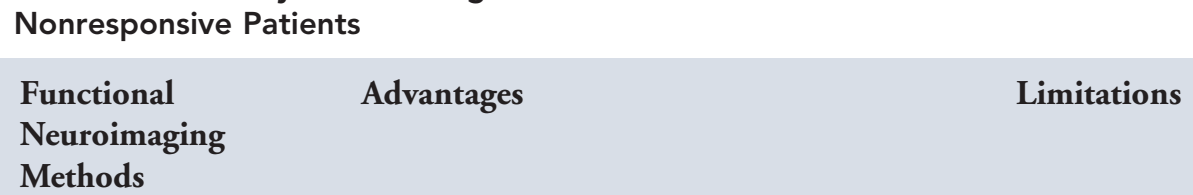

fNIRS

Noninvasive; portable; relatively low cost; nearly noiseless; less sensitive to movement artifacts than fMRI; easier to operate than fMRI; no restriction on paramagnetic medical equipment.

High cost; lack of portability; physical impositions (eg, patient must stay still and in supine position for an extended period of time); no paramagnetic equipment can be present; noisy; susceptible to movement artifacts; lower temporal resolution than EEG (second range).

A relatively new methodology; limited experience with BCI applications; limited spatial resolution $(\sim 3 \mathrm{~cm})$; especially poor resolution of deep brain structures; some susceptibility to movement artifacts; analysis methods under development.

EEG
Noninvasive; portable; relatively low cost; high temporal resolution (millisecond range); silent; no physical impositions (eg, can be applied in the seated and supine positions or when the patient is asleep); vast $\mathrm{BCI}$ experience with different patient populations.

Limited spatial resolution $(\sim 3 \mathrm{~cm})$; especially poor resolution of deep brain structures; susceptible to artifacts from cranial muscles and eye movements; the majority of existing paradigms have limited use for DOC patients (but see Cruse et $\left.\mathrm{al}^{30}\right)$.

$\mathrm{BCI}=$ brain-computer interface; $\mathrm{DOC}=$ disorders of consciousness; $\mathrm{EEG}=$ electroencephalography; $\mathrm{fMRI}=\mathrm{functional}$ magnetic resonance imaging; fNIRS $=$ functional near-infrared spectroscopy; VS = vegetative state.

rarely an option with stable and/or chronic DOC patients. The DOC patients we consider here (VS and MCS) are not able to provide informed consent. For any research, legal approval is required from the patient's family or other legal representative. This is far less likely to be granted for invasive BCI applications, especially when they are not part of treatment protocols, as they may adversely influence the patient's health. For similar reasons, with the exception of rare cases, where the patient requires surgical intervention and the appropriate legal and ethical permissions are already in place, such research is prevented by rulings of ethics boards and other regulatory organizations. Finally, issues of financing and access to medical resources available only to acute patients with specific conditions further prohibit invasive BCI applications in DOC patients.

\section{fMRI BCls}

To date, the most successful attempt to develop a BCI system for DOC patients has used fMRI, a technique that measures the changes in blood flow and oxygenation in the brain, known as hemodynamics. ${ }^{49,50}$ fMRI has several strengths for BCI applications, including its noninvasive nature, global brain coverage of the cortex and deep subcortical structures, and excellent spatial resolution (in the millimeter range).

Owen and colleagues ${ }^{32}$ employed an fMRI-based mental imagery paradigm to assess command following in a patient who had been clinically diagnosed as VS and had been unresponsive for 5 months. The patient was asked to imagine playing tennis (for 30 seconds) when she heard the word tennis, and to relax (for 30 seconds) when she heard the word relax. In a separate spatial imagery task, she was asked to imagine moving around the rooms of her home (for 30 seconds) when she heard the word house, and to relax (for 30 seconds), when she heard the word relax. The patient showed task-specific fMRI activation in the appropriate regions of the supplementary motor area following the instruction to imagine playing tennis, and in the parahippocampal gyrus, the posterior parietal lobe, and the lateral premotor cortex following the instruction to imagine moving from room to room in her house. Moreover, this activity was indistinguishable from that of healthy participants performing the same tasks (Fig 3). ${ }^{33,51}$ The 


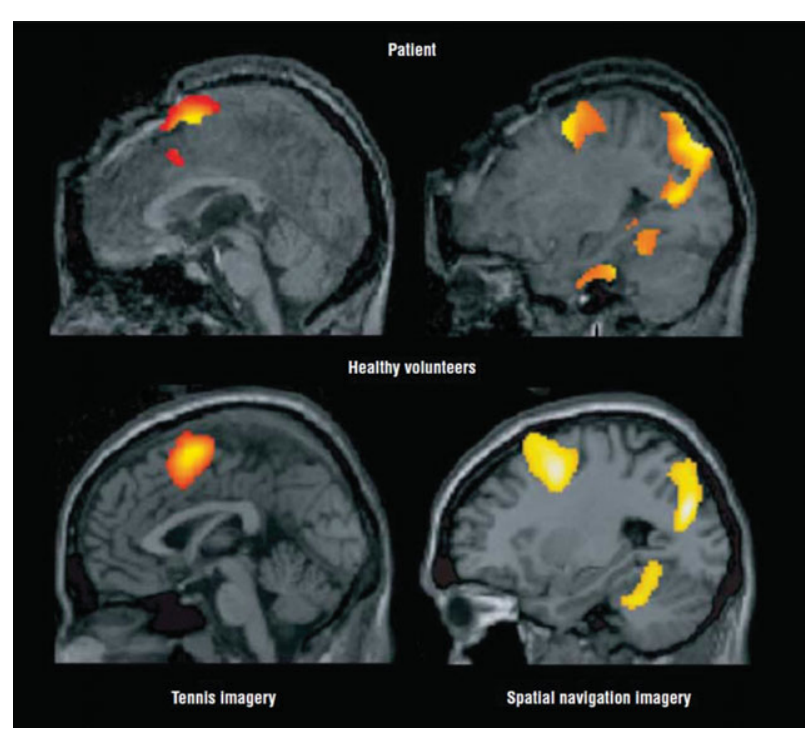

FIGURE 3: Conscious responses to stimuli in a patient who fulfilled all the clinical criteria defining the vegetative state, revealed by functional magnetic resonance imaging. The top panel shows the brain activation in the supplementary motor area during tennis imagery, and the parahippocampal gyrus, posterior parietal lobe, and lateral premotor cortex during imagery of spatial navigation, in the patient. These responses were indistinguishable from that of a group of healthy volunteers $(n=12)$, shown in the bottom panel. Image reproduced with permission from Owen AM, Coleman MR, Boly $M$, et al. Detecting awareness in the vegetative state. Science 2006;313:1402.

patient's fMRI activation was statistically robust, reproducible, task appropriate, and sustained over long time intervals (30 seconds), allowing Owen and colleagues ${ }^{33}$ to conclude that she was responding to the commands by performing the imagery tasks in the absence of any overt action.

Monti et $\mathrm{al}^{32}$ extended this approach to demonstrate that fMRI could also be used to communicate with a nonresponsive patient who was assumed to be in a VS. One type of imagery (tennis or spatial navigation) was mapped to a yes response, and the other to a no response. A single neutral word, answer, was used to cue each response to a question. To decode the answers, each communication scan was compared to 2 localizer scans, during which the patient was asked to simply imagine playing tennis, or imagine moving around his house (see Owen et $\mathrm{al}^{33}$ ). Following 6 autobiographical questions (eg, "Is your father's name Thomas?"), the answers that were decoded from the brain activity matched the factually correct answers (in 5 of the 6 questions), which were unknown to the experimenters at the time. This study demonstrated that the presence of voluntary, reliable, and sustained brain activity in response to command could be used as a proxy for physical behavior, such as move- ment or speech, to facilitate communication with nonresponsive participants. ${ }^{17,32,33}$

In the study described above, 54 VS and MCS patients were tested and, of those, only 5 (4 VS) showed significant changes in fMRI activation during the basic imagery tasks. One interpretation of this finding is that the diagnosis was accurate in the vast majority of cases, and the negative results reflect a genuine lack of awareness in those patients. ${ }^{32}$ Several other factors, however, may also explain these findings. First, it is possible that this technique lacks sensitivity, and thus failed to show activation in patients who might have been engaged in the task. Indeed, it is known that in brain-damaged patients, the coupling of hemodynamics and neuronal firing, which lies at the basis of the fMRI signal, may be very different from that in healthy volunteers. ${ }^{52,53}$ Alternatively, it is possible that in some patients, deficits in language comprehension, decision making, working memory, or executive function may have hampered their efforts to express themselves through the imagery task, yielding brain activity too weak to be interpreted. Consistent with this possibility, a recent report found an MCS patient who showed no distinguishable activation in the mental imagery task, but nonetheless was able to voluntarily modulate his brain activity by allocating visual attention in response to verbal commands. ${ }^{53}$ Finally, in some patients, functional reorganization of the brain following the injury may have produced highly atypical, and therefore uninterpretable, patterns of fMRI activation.

Communication via fMRI BCIs has been attempted in 6 other DOC patients, 5 MCS and 1 LIS. ${ }^{55}$ Bardin et $\mathrm{al}^{55}$ used binary paradigms involving motor imagery, similar to those used by Monti and colleagues, and a multiple-choice paradigm, adapted from Sorger et al. ${ }^{37}$ In a novel application of this 4-choice paradigm, the experimenters presented each patient, at their bedside, with 1 playing card, which could be 1 of 4 , differing in 2 dimensions (suit and face). Subsequently, while inside the fMRI scanner, each patient was aurally provided with the 4 options for the suit and face of the card, and was asked to perform a mental imagery task (swimming or tennis) to indicate the correct card, for each of the 2 dimensions. The authors reported a communication signal in 1 of the 6 patients. Although the patient showed significant brain activity to the task, this activity conveyed incorrect responses to the 2 questions asked, with respect to the face and the suit of the card. However, the patient was able to correctly show command following behaviorally at the bedside, and by modulating her brain activity in the scanner, according to the instructions of the binary mental imagery task. The authors suggested 
that a delay in the timing of the hemodynamic signal to the patient's response might explain why the neural responses to 2 stimuli proximal in time could not be disambiguated with traditional fMRI analyses. ${ }^{55}$ This study highlighted the issue of unknown delay range of the neural signal in this patient group, which could be driven by an unusual coupling of hemodynamics and neuronal firing, as compared to healthy individuals. ${ }^{52,53}$ Although the optimal interval for a reliable measurement of the neural response is not known, the 30-second intervals reported by Owen, Monti, and colleagues have so far yielded unequivocal results of successful communication in 1 patient, and command following in 6 patients, documented in published reports. A systematic study of the delay range would be necessary to determine the optimal response interval, and furthermore this parameter might differ across neuroimaging methodologies (fMRI, fNIRS, EEG).

A second patient reported by Bardin et a ${ }^{55}$ raised a different issue relevant to communicating with DOC patients through neuroimaging BCIs. This patient could show command following by using motor imagery (swimming) in 2 different visits, but could not use the motor imagery task to produce robust brain activity that could be used for binary (yes/no) communication. Several factors could be behind this patient's failure to communicate. ${ }^{56,57}$ The patient's profile of cognitive deficit, in particular her short-term memory reserve, may underlie her inability to communicate. Beyond command following, where the patient has to perform a task in response to a specific command such as tennis or swim to communicate, the patient must be able to perform at least 2 additional processes. First, the patient must be able to find the answer to the question that is being asked. In addition, the patient must also be able to abstract the demand characteristic of the task (ie, imagine playing tennis/swimming), to a particular answer word (yes or no), which applies in some situations (ie, questions whose answer is that word) but not in others. A patient with a pronounced memory deficit may not be able either to think of the answer and/or to maintain in shortterm memory the abstract link between the arbitrary response function (ie, a specific form of motor imagery) and the answer word to a question (yes or no). This patient highlights the need for new paradigms that rely on more intuitive response modes, to maximize the chance that patients with very limited cognitive reserves will be reached.

At least the issue of delayed response might be resolved with more sophisticated neuroimaging analysis methods, ${ }^{58}$ such as multivoxel pattern analysis (MVPA).
MVPA is an PMRI analysis technique that is highly sensitive to the information content in the neural signal. Traditional univariate fMRI analyses average across activations in a brain region, and compare overall changes in signal strength between different types of conditions. ${ }^{58}$ MVPA, conversely, does not discard the information relating to the patterns of activity within that brain region. As such, it is capable of dissociating overlapping neural patterns to different stimuli or mental states, ${ }^{60,61}$ which could not be disentangled with univariate methods. ${ }^{61}$ By dissociating several mental states/responses elicited by a single command, ${ }^{63,64}$ MVPA also has the potential to expand communication from binary responses to multiple-choice answers. For example, although this is still in the future, with MVPA it may eventually be possible to ask a patient to express how much pain he/she feels on a sliding scale from 1 to 10 , by imagining the appropriate number. In a follow-up study, Bardin et al ${ }^{58}$ provided the first proof of principle that MVPA can decode a patient's answers elicited from a multiple-choice response paradigm. In the case described above, ${ }^{55}$ conventional fMRI analysis could not distinguish which was the patient's response between 2 choices in each question relating to the 2 card features (suit or face). For each question, 2 options, temporally proximal in the 4-choice stimuli presentation, produced statistically significant responses that were undistinguishable with univariate analysis. By contrast, an MVPA classifier was able to disambiguate the response patterns for each question, by classifying the response to the correct option (selected prior to the scanning session) above chance, and the response to the incorrect option at chance, with a significant difference between the 2 classifications.

MVPA methods can also be applied in real time, ${ }^{65-68}$ and present exciting possibilities for communication without perceptible delay between the question and the interpretation of the response. With these methods, however, classification accuracy is strongly dependent on the amount of available fMRI data. This may be a problem for VS patients, where the scanning time is often limited for physical reasons, for example, the patient experiences difficulty lying supine for long periods of time. Moreover, one has to consider that VS patients may become exhausted easily.

Other approaches have also been used to explore the potential uses of fMRI for BCI-related applications. In a study with healthy participants, Sorger and colleagues $^{37}$ were able to generate the differential blood oxygenation level-dependent (BOLD) responses necessary to answer a 4-choice question within the length of a single, 
1-minute trial. To express their choice, participants had the option of 1 of 2 tasks, performed at 1 of 4 moments in time, which were indicated by a highlighted letter on the screen and offset by 5 seconds one from the other. Thus, the BOLD responses could be differentiated with respect to at least 2 of 3 features of the BOLD signal: its source location, onset, and offset. An automated decoding procedure deciphered the answer by analyzing the generated single-trial BOLD responses online. Participants' answers were decoded correctly with a mean accuracy of $94.9 \%$, ranging from $75 \%$ to $100 \%$. This study made an important contribution by demonstrating that single-trial (ie, brief, or, 1 minute long) fMRI time courses can be used as a robust source of information for decoding responses. Furthermore, it showed that fMRI can be used to communicate multiple-choice answers online/in real time, and within a reasonable response time scale (eg, 1 minute). This length of time does not introduce excessive time pressures, and may prove patient-friendly. However, the applicability of this design for communication with nonresponsive patients would be limited by its reliance on visual processing.

Although, as we have discussed, fMRI has great strengths for BCI applications, including its noninvasive nature, global brain coverage, and excellent spatial resolution of specific brains structures, it also comes with significant limitations, which restrict its widespread use in DOC patients. In particular, its high cost, lack of portability, and physical impositions on some patients (eg, patients must not wear paramagnetic equipment, must refrain from any minor movement, and must be able to cope with the loud noise of the fMRI scanner) make it unlikely that fMRI will provide the ultimate communicative solution that DOC patients require in real life situations. fNIRS and EEG, however, are not susceptible to these same problems, and provide exciting opportunities to extend these fMRI developments.

\section{fNIRS BCls}

fNIRS exploits the penetrability of biological tissue by light in the near-infrared spectrum $(700-1,000 \mathrm{~nm})$ to infer neural activity. The amount of near-infrared light at specific wavelengths that is absorbed by blood vessels varies depending on the concentration of oxygenated and deoxygenated hemoglobin. ${ }^{69,70}$ Using head-mounted near-infrared emitters and sensors, fNIRS provides a noninvasive hemodynamic measure of cortical activity. The main advantage of fNIRS over fMRI is that it is portable. Furthermore, in contrast to fMRI, fNIRS is also a relatively comfortable method. It is nearly noiseless, does not expose patients to a high magnetic field, thus avoiding the restrictions imposed by paramagnetic medical equipment, and is less sensitive to movement artifacts. Moreover, fNIRS is relatively affordable, less technically demanding, and easier to operate than fMRI. These qualities make fNIRS a viable technology for use at the patients' bedside.

Although it is in its infancy, some early applications have demonstrated the potential of fNIRS as a BCI method. Naito and colleagues ${ }^{71}$ mapped 2 mental imagery tasks, calculation and singing, to yes/no responses, and were able to detect responses with fNIRS in $40 \%$ of 17 CLIS patients. The brain response for these patients could be decoded with $74 \%$ accuracy. As the first BCI method successfully applied in CLIS patients, this study highlighted the future potential of fNIRS in this field.

Although fNIRS has certain benefits over fMRI, it also suffers from technological challenges that limit its application for BCI systems, at least in its current state. In particular, fNIRS only allows reliable measurement of hemodynamic responses in cortical tissue that is close to the head surface, up to approximately $3 \mathrm{~cm}$ in depth. Thus, brain activation in deeper subcortical structures, accessible with fMRI, cannot be targeted. Moreover, the spatial resolution of fNIRS, in the range of a few cubic centimeters, is considerably lower than the resolution that can be obtained with fMRI. Thus, BCI paradigms that employ fNIRS must be based upon neural responses that are relatively broad. Future improvements in the development of multichannel fNIRS systems promise to address this issue. ${ }^{72}$ Another area that will benefit greatly from further research and development is that of analyses methods, which are still relatively rudimentary in fNIRS, as compared to those used for fMRI. For example, the limited spatial resolution may be overcome by employing more sensitive data analysis techniques such as MVPA that maximize the likelihood of decoding different mental states from widely distributed brain activation patterns.

\section{EEG BCls}

EEG is another noninvasive, portable, and relatively inexpensive neuroimaging method that has been used extensively in BCI applications. The experience gained with its use in many populations, from healthy participants to severely paralyzed and LIS patients, lends itself to application in nonresponsive DOC patients. The EEG signal that is measured on the scalp results from neural activity originating in the cortex ${ }^{73}$ which can be captured with high temporal resolution, in the millisecond range. However, in contrast to fMRI, EEG provides limited spatial resolution (centimeter range) that strongly decreases with 
the depth of the source. Similar to fNIRS, EEG is silent, less physically demanding for the patient (for example, it can be applied in the seated and supine positions, or even when the patient is asleep), and easier to operate than fMRI. EEG is susceptible to artifacts from electromyographic activity from cranial muscles, and electrooculographic activity from eye movements, but sophisticated analysis methods can eliminate these artifacts. Below, we review the EEG markers that hold promise for BCI systems in nonresponsive DOC patients, as well as a number of challenges that thus far have limited the application of this technology in this patient group.

One prominent component of event-related potentials (ERPs; electrical potentials related to events/stimuli) that has been widely used for EEG BCI applications in responsive patients is the $\mathrm{P} 300$ (or P3). The $\mathrm{P} 300$ is a large wave peaking over parietal regions 300 to 350 milliseconds after the presentation of a target or the stimulus that is being looked out for and/or that grabs attention. ${ }^{74}$ This ERP component is often investigated in the context of the so-called oddball paradigm, ${ }^{75}$ in which rare deviant tones are presented among frequent standard tones, and stand out as oddballs that generate a reliable P300. In healthy participants, the P300 can be elicited by passive paradigms (eg, just listening), especially for stimuli of particular significance, like a participant's own name, ${ }^{76}$ and increases substantially when participants actively attend, for example, by counting a rare stimulus in a sequence of sounds. ${ }^{77}$ About 20 to $25 \%$ of patients with DOC show a P300 effect. ${ }^{30}$ Moreover, the modulation of the P300 by manipulations of conscious perception, such as stimulus masking, attention manipulations, and anesthesia, highlights its usefulness as a marker of awareness. However, its amplitude increase in active paradigms, as compared to passive paradigms, is likely to be a more reliable indicator of awareness than the mere presence of this component, as the P300 can be elicited even when participants are not conscious of the stimuli. $^{78,79}$

The active/willful modulation of the P300 may be employed to establish an EEG BCI method, where the patient's response is expressed through attention to specific (eg, auditory) stimuli, according to the operator's commands. Schnakers presented a CLIS patient with her own and other people's names, and asked her to count specific names. ${ }^{80}$ Although the patient's own name elicited a P300 in all conditions, the P300 elicited when the patient was specifically asked to count her own name was significantly larger in amplitude than that elicited by her own name when she was asked to count other names. This suggested that the patient was able to follow instructions, and consciously processed the meaning of the words she had heard. In another study, Schnakers and colleagues ${ }^{81}$ tested 14 DOC (MCS and VS) patients with a similar technique, and showed that the MCS patients exhibited a P300 to their own names, in both active (counting) and passive (listening) conditions. Like controls, this P300 was larger in the active condition than in the passive condition, suggesting voluntary compliance with task instructions. By contrast, the VS patients did not show any P300 differences between the active and passive conditions, suggesting that they were unable to comply with task instructions in the active condition.

Similar to the study by Monti et al, ${ }^{32}$ at least 2 alternative interpretations may explain the negative result observed in the VS patients. One interpretation is that the diagnosis for these patients was accurate; they were not aware of the task they were being asked to perform and therefore did not produce any responses. An alternative explanation is that the task lacked sensitivity and thus failed to detect VS patients who retained some level of consciousness, but were perhaps unable to understand the instructions and/or to sustain attention for a sufficient period to perform the task. This paradigm may permit the detection of voluntary brain function in patients who show very limited signs of awareness and thus has potential to be used as a BCI communication paradigm. However, further work is needed to establish its suitability for detecting awareness in VS patients, whose attention and cognitive faculties are subject to drastic fluctuations over time, and may therefore be detected only by methods robust to noise and sensitive to weak responses.

A completely different approach for using the P300 modulation as a BCI method was originally proposed by Farwell and Donchin. ${ }^{82}$ In this paradigm, participants were presented with a screen displaying a matrix of letters $\mathrm{A}$ to $\mathrm{Z}$ and asked to choose a letter they wished to write on the screen. Columns and rows of the matrix flashed in a pseudorandomized order. By identifying which column and row flashed immediately prior to an evoked P300 component, it was possible to deduce that the letter at their intersection was the attended one and therefore the one the participant wished to write. Although this BCI technique proved very efficient for severely paralyzed and locked-in patients, ${ }^{38,83}$ its reliance on visual presentation limits its applicability to VS patients.

Efforts to translate this paradigm to the auditory modality ${ }^{42,43}$ have met with a number of problems, even in healthy controls. For instance, visual information can be presented in parallel, that is, an entire matrix of 26 letters can be presented at once, whereas equivalent auditory stimuli must be presented sequentially. Even if the 
many items of the matrix could be coded by fewer auditory stimuli, compared to the visual paradigm, remembering the coding system requires focusing of attention for a longer period, while keeping much of the information in short-term memory. Such cognitive demands would very likely hamper the performance of brain-damaged patients, especially those assumed to be in the VS.

Sellers and Donchin ${ }^{84}$ introduced a simpler version of this paradigm. They developed the so-called 4-choice speller, in which participants were presented with only 4 visual or auditory stimuli, namely, yes, no, pass, and end. This paradigm has been tested with LIS (ALS) patients, ${ }^{85}$ all of whom exhibited a P300 effect to the stimulation, but classification accuracies were lower in the auditory than in the visual version of the task. For reasons similar to those discussed above, DOC patients are likely to find this task more difficult than LIS patients. Other studies with late stage ALS patients have used the self-regulation of slow-cortical potentials to assess and train conditional learning $^{86}$ and cognitive function, including the ability to perform simple computations ${ }^{87}$ in these patients. However, the translation of such paradigms, developed for patients who are known to be conscious and have preserved cognitive responsivity, to patients whose clinical diagnosis precludes the presence of conscious awareness (ie, VS patients), faces several major challenges. In particular, they rely on training, which is not generally an option with VS/MCS patients. These challenges point to the need for continued development of EEG auditory $\mathrm{BCI}$ paradigms that are amenable to the limitations of nonresponsive (DOC) and especially VS patients.

Another type of active EEG paradigm has utilized attempted, or imagined, motor actions, which produce neural activity that can be measured with EEG, as it can with fMRI. Kotchoubey and colleagues ${ }^{88}$ described a CLIS patient whose slow EEG activity significantly differed between trials when he was asked to try to move the left as compared to the right hand. In healthy participants, motor imagery also produces clearly distinguishable modulation of EEG sensorimotor rhythms (SMRs), ${ }^{89,90}$ similar to those seen during motor execution. ${ }^{91}$ Kübler and colleagues showed that LIS patients with ALS could learn to modulate their SMRs with $>70 \%$ accuracy, but did not test VS patients with this paradigm. $^{92}$

Goldfine and colleagues ${ }^{93}$ were the first to translate to the EEG motor imagery tasks (imagine swimming/ stop imagining) and spatial navigation tasks (imagine walking around your home/stop imagining) similar to those used with fMRI. ${ }^{32,33,55}$ They tested 5 healthy controls and 3 DOC patients, 2 MCS and 1 LIS. The authors reported variability in the patients' responses,

\section{Healthy Volunteer}

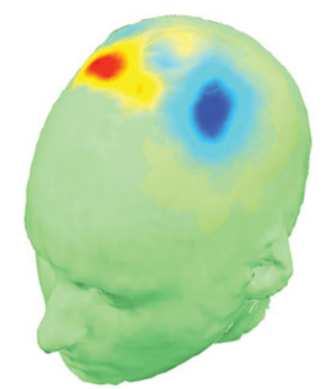

Vegetative Patient

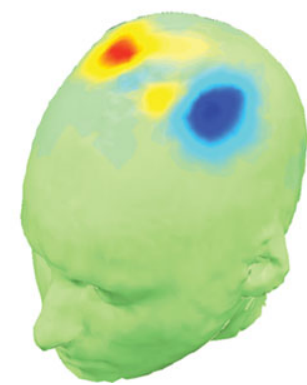

FIGURE 4: Conscious responses to stimuli in a patient who fulfilled all the clinical criteria defining the vegetative state, revealed by electroencephalography (EEG). The EEG response during a motor imagery task, shown in this figure, reveated clear foci over the hand and toe motor areas, which were formally identical when compared between a healthy control participant and a vegetative state patient. Image reproduced with permission from Cruse D, Chennu S, Chatelle $C$, et al. Bedside detection of awareness in the vegetative state: a cohort study. Lancet 2011;6736:61224-61225.

which allowed only limited conclusions to be drawn about the applicability of these paradigms to patients with disorders of consciousness. In the first patient, the authors observed that the task-related signals were different from those observed in the healthy controls. In the second patient, the authors observed variability between the task-related signals produced during 2 different visits. The signal from the first visit was consistent across runs, but the signal from the second visit was inconsistent across runs, and was classified as indeterminate. The third patient showed a similarly indeterminate pattern during both visits. The authors concluded that assessment of larger sample sizes of both healthy controls and patients groups would be needed before this task could be used as a clinically diagnostic tool. However, as the first study to translate to EEG the motor imagery paradigms that have been used successfully in fMRI, this work is an important proof of principle.

Cruse et $\mathrm{al}^{31}$ have shown the most promising application of EEG as a BCI technology for VS patients to date (Fig 4). They instructed a group of $16 \mathrm{VS}$ patients to perform 2 motor imagery tasks, imagining moving their right hand and imagining moving their toes. By submitting the EEG data associated with each task command to a cross-validated support vector machine classifier, Cruse et $\mathrm{al}^{31}$ were able to demonstrate that 3 of the $16 \mathrm{VS}$ patients were able to reliably and consistently modulate their SMR, with classifier outputs of up to $78 \%$ accuracy. Such a result provides the necessary proof of concept for the use of motor imagery as a BCI method and with the future application of real time data analyses may allow for bedside communication with VS patients. 


\section{Summary}

We have reviewed the advantages and disadvantages of 3 noninvasive neuroimaging technologies (fMRI, fNIRS, and EEG) for use in BCI applications designed to communicate with nonresponsive DOC patients. Although the most advanced methods for this patient group have so far used fMRI, given its cost and lack of portability it is unlikely that fMRI will provide a long-term communication system for any individual patient. The development of efficient and user-friendly BCI systems for nonresponsive DOC patients will hinge on the translation of these advances to cheaper and more portable technologies, such as fNIRS and EEG. Cruse et $\mathrm{al}^{31}$ showed that detection of command following in patients previously thought to be in a VS is possible with EEG, thus moving a step closer to bedside communication with entirely nonresponsive DOC patients.

When a brain-injured patient with disorders of consciousness effectively uses a neuroimaging system to follow commands ${ }^{33}$ and even communicate, ${ }^{32}$ a diagnosis of VS is rendered erroneous. The mismatch between a patient's clinical diagnosis and his/her level of residual cognition, detected with neuroimaging, raises questions about how to place this patient in the current spectrum of diagnostic categories. Some authors have suggested that such patients represent a new syndrome that has yet to be fully characterized. ${ }^{57,94}$ Furthermore, there is a moral imperative to communicate and involve these patients in important life-altering decisions ${ }^{95}$ routinely made on their behalf by other people.

To enable fully fledged real time BCI communication, it will be important to begin by identifying those patients, whether VS or MCS, most capable of using such systems. As we have discussed, DOC patients vary dramatically in their level of arousal and awareness. The inclusion of passive $\mathrm{fMRI}^{28,96}$ and EEG tasks $22,30,97$ within a hierarchical procedure will allow for the characterization of the spared cognitive abilities of each patient, which could then be used to determine the most appropriate form of BCI to employ in that individual. ${ }^{97}$ Finally, BCI systems with rapid, online decoding of brain responses could be adapted to the individual needs of high-functioning patients, to enable true interindividual communication.

\section{Acknowledgment}

This work was supported by the DECODER Project, funded by the European Commission in the 7th Framework Programme (2007-2013; L.N., M.M.M., A.K., B.S., R.G., B.K., A.M.O). Additional support was pro- vided by the Medical Research Council (U.1055.01.002.00001.01), the James S. McDonnell Foundation, and the Canada Excellence Research Chairs Program (L.N., D.C., A.M.O.).

\section{Potential Conflicts of Interest}

Nothing to report.

\section{REFERENCES}

1. Lulé $D$, Zickler $C$, Häcker $S$, et al. Life can be worth living in locked-in syndrome. Prog Brain Res 2009;177:339-351.

2. Schnakers C, Majerus S, Goldman S, et al. Cognitive function in the locked-in syndrome. J Neurol 2008;255:323-330.

3. Pantke KH. Locked-in: imprisoned in your own body. Pflege Aktuell 1998;52:240-244.

4. Tavalaro J, Tayson R. Look up for yes. New York, NY: Kodansha International, 1997.

5. Kübler A, Kotchoubey B. Brain-computer interfaces in the continuum of consciousness. Curr Opin Neurol 2007;20:643-649.

6. Bauer G, Gerstenbrand F, Rumpl E. Varieties of the locked-in syndrome. J Neurol 1979;221:77-91.

7. Bruno M, Bernheim JL, Schnakers C, Laureys S. Locked-in: don't judge a book by its cover. J Neurol Neurosurg Psychiatry 2008; $79: 2$.

8. Kübler A, Birbaumer N. Brain-computer interfaces and communication in paralysis: extinction of goal directed thinking in completely paralysed patients? Clin Neurophysiol 2008;119:2658-2666.

9. Abe K, Fujimura H, Toyooka K, et al. Cognitive function in amyotrophic lateral sclerosis. J Neurol Sci 1997;148:95-100.

10. Abrahams S, Goldstein LH, Lloyd CM, et al. Cognitive deficits in non-demented amyotrophic lateral sclerosis patients: a neuropsychological investigation. J Neurol Sci 1995;129(suppl):54-55.

11. Ludolph $A C$, Langen $\mathrm{KJ}$, Regard $\mathrm{M}$, et al. Frontal lobe function in amyotrophic lateral sclerosis: a neuropsychologic and positron emission tomography study. Acta Neurol Scand 1992;85:81-89.

12. The Multi-Society Task Force on PVS. Medical aspects of the persistent vegetative state. N Engl J Med 1994;330:1499-1508.

13. Laureys S, Owen AM, Schiff ND. Brain function in coma, vegetative state, and related disorders. Lancet Neurol 2004;3:537-546.

14. Adams JH, Graham DI, Jennett B. The neuropathology of the vegetative state after an acute brain insult. Brain 2000;123: 1327-1338

15. Laureys S, Celesia GG, Cohadon F, et al. Unresponsive wakefulness syndrome: a new name for the vegetative state or apallic syndrome. BMC Med 2010;8:68.

16. Giacino JT, Ashwal S, Childs N, et al. The minimally conscious state: definition and diagnostic criteria. Neurology 2002;58:349-353.

17. Owen AM, Coleman MR. Using neuroimaging to detect awareness in disorders of consciousness. Funct Neurol 2008;23:189-194.

18. Monti MM, Coleman MR, Owen AM. Neuroimaging and the vegetative state: resolving the behavioral assessment dilemma? Ann N Y Acad Sci 2009;1157:81-89.

19. Schnakers C, Vanhaudenhuyse A, Giacino J, et al. Diagnostic accuracy of the vegetative and minimally conscious state: clinical consensus versus standardized neurobehavioral assessment. BMC Neurol 2009;9:35.

20. Andrews K, Murphy L, Munday R, Littlewood C. Misdiagnosis of the vegetative state: retrospective study in a rehabilitation unit. BMJ 1996;313:13-16. 
21. Childs NL, Mercer WN, Childs HW. Accuracy of diagnosis of persistent vegetative state. Neurology 1993;43:1465-1467.

22. Schnakers C, Majerus S, Laureys S. Bispectral analysis of electroencephalogram signals during recovery from coma: preliminary findings. Neuropsychol Rehabil 2005;15:381-388.

23. Menon DK, Owen AM, Williams EJ, et al. Cortical processing in persistent vegetative state. Wolfson Brain Imaging Centre Team. Lancet 1998;352:200.

24. Kotchoubey B, Kaiser J, Bostanov V, et al. Recognition of affective prosody in brain-damaged patients and healthy controls: a neurophysiological study using EEG and whole-head MEG. Cogn Affect Behav Neurosci 2009;9:153-167.

25. Owen AM, Menon DK, Johnsrude IS, et al. Detecting residual cognitive function in persistent vegetative state. Neurocase 2002; 8:394-403.

26. Coleman MR, Davis MH, Rodd JM, et al. Towards the routine use of brain imaging to aid the clinical diagnosis of disorders of consciousness. Brain 2009;132:2541-2552.

27. Fischer C, Dailler F, Morlet D. Novelty P3 elicited by the subject's own name in comatose patients. Clin Neurophysiol 2008;119: 2224-2230.

28. Coleman MR, Rodd JM, Davis $\mathrm{MH}$, et al. Do vegetative patients retain aspects of language comprehension? Evidence from fMRI. Brain 2007;130:2494-2507.

29. Perrin F, Schnakers $C$, Schabus M, et al. Brain response to one's own name in vegetative state, minimally conscious state, and locked-in syndrome. Arch Neurol 2006;63:562-569.

30. Kotchoubey B, Lang S, Mezger G, et al. Information processing in severe disorders of consciousness: vegetative state and minimally conscious state. Clin Neurophysiol 2005;116:2441-2453.

31. Cruse D, Chennu S, Chatelle C, et al. Bedside detection of awareness in the vegetative state: a cohort study. Lancet $2011 ; 6736$ : $61224-61225$

32. Monti MM, Vanhaudenhuyse A, Coleman MR, et al. Willful modulation of brain activity in disorders of consciousness. $N$ Engl J Med 2010;362:579-589.

33. Owen AM, Coleman MR, Boly $M$, et al. Detecting awareness in the vegetative state. Science 2006;313:1402.

34. van Gerven M, Farquhar J, Schaefer R, et al. The brain-computer interface cycle. J Neural Eng 2009;6:041001.

35. deCharms RC, Maeda F, Glover GH, et al. Control over brain activation and pain learned by using real-time functional MRI. Proc Natl Acad Sci U S A 2005;102:18626-18631.

36. Lee JH, Ryu J, Jolesz FA, et al. Brain-machine interface via realtime fMRI: preliminary study on thought-controlled robotic arm. Neurosci Lett 2009:450:1-6.

37. Sorger B, Dahmen B, Reithler J, et al. Another kind of "BOLD Response": answering multiple-choice questions via online decoded single-trial brain signals. Prog Brain Res 2009;177: $275-292$.

38. Nijboer F, Sellers EW, Mellinger J, et al. A P300-based brain-computer interface for people with amyotrophic lateral sclerosis. Clin Neurophysiol 2008;119:1909-1916.

39. Sitaram R, Caria A, Veit R, et al. FMRI brain-computer interface: a tool for neuroscientific research and treatment. Comput Intell Neurosci 2007;25487

40. Yoo S-S, Fairneny T, Chen N-K, et al. Brain-computer interface using fMRI: spatial navigation by thoughts. Neuroreport 2004;15: 1591-1595.

41. Gill-Thwaites H, Munday R. The Sensory Modality Assessment and Rehabilitation Technique (SMART): a valid and reliable assessment for vegetative state and minimally conscious state patients. Brain Inj 2004;18:1255-1269.
42. Furdea A, Halder S, Krusienski DJ, et al. An auditory oddball (P300) spelling system for brain-computer interfaces. Psychophysiology 2009;46:617-625.

43. Klobassa DS, Vaughan TM, Brunner $P$, et al. Toward a highthroughput auditory P300-based brain-computer interface. Clin Neurophysiol 2009;120:1252-1261.

44. Schalk G, Miller KJ, Anderson NR, et al. Two-dimensional movement control using electrocorticographic signals in humans. J Neural Eng 2008;5:75-84.

45. Miller KJ, denNijs $M$, Shenoy $P$, et al. Real-time functional brain mapping using electrocorticography. Neuroimage 2007;37: 504-507.

46. Ramsey NF, van de Heuvel MP, Kho KH, Leijten FSS. Towards human $\mathrm{BCl}$ applications based on cognitive brain systems: an investigation of neural signals recorded from the dorsolateral prefrontal cortex. IEEE Trans Neural Syst Rehabil Eng 2006;14: 214-217.

47. Leuthardt EC, Schalk G, Wolpaw JR, et al. A brain-computer interface using electrocorticographic signals in humans. J Neural Eng 2004:1:63-71.

48. Guenther FH, Brumberg JS, Wright EJ, et al. A wireless brainmachine interface for real-time speech synthesis. PLoS One 2009; 4:e8218.

49. Ogawa S, Menon RS, Tank DW, et al. Functional brain mapping by blood oxygenation level-dependent contrast magnetic resonance imaging. A comparison of signal characteristics with a biophysical model. Biophys J 1993;64:803-812.

50. Kwong KK, Belliveau JW, Chesler DA, et al. Dynamic magnetic resonance imaging of human brain activity during primary sensory stimulation. Proc Natl Acad Sci U S A 1992;89:5675-5679.

51. Boly M, Coleman MR, Davis $\mathrm{MH}$, et al. When thoughts become action: an $\mathrm{fMRI}$ paradigm to study volitional brain activity in noncommunicative brain injured patients. Neuroimage 2007;36: 979-992.

52. Gsell W, De Sadeleer C, Marchalant Y, et al. The use of cerebra blood flow as an index of neuronal activity in functional neuroimaging: experimental and pathophysiological considerations. J Chem Neuroanat 2000;20:215-224.

53. Rossini PM, Altamura C, Ferretti A, et al. Does cerebrovascular disease affect the coupling between neuronal activity and local haemodynamics? Brain 2004;127:99-110

54. Monti MM, Pickard JD, Owen AM. Visual cognition in disorders of consciousness: from V1 to top-down attention. Hum Brain Mapp 2012. doi: 10.1002/hbm.21507. [Epub ahead of print].

55. Bardin JC, Fins JJ, Katz DI, et al. Dissociations between behavioural and functional magnetic resonance imaging-based evaluations of cognitive function after brain injury. Brain 2011;134 769-782.

56. Boly M. Measuring the fading consciousness in the human brain Curr Opin Neurol 2011;24:394-400.

57. Laureys S, Schiff ND. Coma and consciousness: paradigms (re)framed by neuroimaging. Neuroimage 2012;61:478-491.

58. Bardin JC, Schiff ND, Voss HU. Pattern classification of volitional functional magnetic resonance imaging responses in patients with severe brain injury. Arch Neurol 2012;69:176-181.

59. Friston KJ, Holmes AP, Poline JB, et al. Analysis of fMRI time-series revisited. Neuroimage 1995;2:45-53.

60. deCharms RC. Reading and controlling human brain activation using real-time functional magnetic resonance imaging. Trends Cogn Sci 2007;11:473-481

61. deCharms RC. Applications of real-time fMRI. Nat Rev Neurosci 2008:9:720-729.

62. Haynes J-D, Rees G. Decoding mental states from brain activity in humans. Nat Rev Neurosci 2006;7:523-534. 
63. Chadwick MJ, Hassabis D, Weiskopf N, Maguire EA. Decoding individual episodic memory traces in the human hippocampus. Curr Biol 2010;20:544-547.

64. Kay KN, Naselaris T, Prenger RJ, Gallant JL. Identifying natural images from human brain activity. Nature 2008;452:352-355

65. Caria A, Sitaram R, Birbaumer N. Real-time fMRI: a tool for local brain regulation. Neuroscientist 2011 [Epub ahead of print].

66. Sitaram R, Lee S, Ruiz S, et al. Real-time support vector classification and feedback of multiple emotional brain states. Neuroimage $2011 ; 56: 753-765$

67. Lee JH, Marzelli M, Jolesz FA, Yoo SS. Automated classification of fMRI data employing trial-based imagery tasks. Med Image Anal 2009:13:392-404.

68. LaConte SM, Peltier SJ, Hu XP. Real-time fMRI using brain-state classification. Hum Brain Mapp 2007;28:1033-1044.

69. Irani F, Platek SM, Bunce S, et al. Functional near infrared spectroscopy (fNIRS): an emerging neuroimaging technology with important applications for the study of brain disorders. Clin Neuropsychol 2007;21:9-37.

70. Villringer A, Chance B. Non-invasive optical spectroscopy and imaging of human brain function. Trends Neurosci 1997;20:435-442.

71. Naito M, Michioka $Y$, Ozawa $K$, et al. Communication means for totally locked-in ALS patients based on changes in cerebral blood volume measured with near-infrared light. IEICE Trans Inf Syst 2007;90:1028-1037.

72. Joseph DK, Huppert TJ, Franceschini MA, Boas DA. Diffuse optical tomography system to image brain activation with improved spatial resolution and validation with functional magnetic resonance imaging. Appl Opt 2006;45:8142-8151.

73. Niedermeyer E, da Silva L. Electroencephalography: basic principles, clinical applications, and related fields. Philadelphia, PA: Lippincott Williams \& Wilkins, 2005

74. Donchin E. Presidential address, 1980. Surprise!...Surprise? Psychophysiology 1981;18:493-513.

75. Duncan-Johnson CC, Donchin E. On quantifying surprise: the variation of event-related potentials with subjective probability. Psychophysiology 1977;14:456-467.

76. Fischler I, Jin YS, Boaz TL, et al. Brain potentials related to seeing one's own name. Brain Lang 1987;30:24-62.

77. Lang S, Kotchoubey B, Lutz A, Birbaumer N. What are you doing when you are doing nothing? ERP components without a cognitive task. Z Exp Psychol 1997;44:138-162.

78. Bastuji H, Perrin F, Garcia-Larrea L. Semantic analysis of auditory input during sleep: studies with event related potentials. Int J Psychophysiol 2002;46:243-255

79. Shevrin H. Event-related markers of unconscious processes. Int J Psychophysiol 2001;42:209-218.

80. Schnakers $C$, Perrin F, Schabus $M$, et al. Detecting consciousness in a total locked-in syndrome: an active event-related paradigm. Neurocase 2009;15:271-277.

81. Schnakers C, Perrin F, Schabus M, et al. Voluntary brain processing in disorders of consciousness. Neurology 2008;71:1614-1620.
82. Farwell LA, Donchin E. Talking off the top of your head: toward a mental prosthesis utilizing event-related brain potentials. Electroencephalogr Clin Neurophysiol 1988;70:510-523.

83. Kleih SC, Kaufmann T, Zickler $\mathrm{C}$, et al. Out of the frying pan into the fire-the P300-based $\mathrm{BCl}$ faces real-world challenges. Prog Brain Res 2011:194:27-46.

84. Sellers EW, Donchin E. A P300-based brain-computer interface: initial tests by ALS patients. Clin Neurophysiol 2006;117:538-548.

85. Kübler $A$, Furdea $A$, Halder $S$, et al. A brain-computer interface controlled auditory event-related potential (p300) spelling system for locked-in patients. Ann N Y Acad Sci 2009;1157:90-100.

86. Iversen I, Ghanayim N, Kübler A, et al. Conditional associative learning examined in a paralyzed patient with amyotrophic lateral sclerosis using brain-computer interface technology. Behav Brain Funct 2008:4:53.

87. Iversen $\mathrm{IH}$, Ghanayim N, Kübler $\mathrm{A}$, et al. A brain-computer interface tool to assess cognitive functions in completely paralyzed patients with amyotrophic lateral sclerosis. Clin Neurophysiol 2008;119:2214-2223.

88. Kotchoubey B, Lang S, Herb E, et al. Stimulus complexity enhances auditory discrimination in patients with extremely severe brain injuries. Neurosci Lett 2003;352:129-132.

89. Cincotti F, Mattia D, Babiloni $C$, et al. The use of EEG modifications due to motor imagery for brain-computer interfaces. IEEE Trans Neural Syst Rehabil Eng 2003;11:131-133.

90. Wolpaw JR, McFarland DJ, Neat GW, Forneris CA. An EEG-based brain-computer interface for cursor control. Electroencephalogr Clin Neurophysiol 1991;78:252-259.

91. Lotze M, Montoya P, Erb M, et al. Activation of cortical and cerebellar motor areas during executed and imagined hand movements: an fMRI study. J Cogn Neurosci 1999;11:491-501.

92. Kübler A, Nijboer F, Mellinger J, et al. Patients with ALS can use sensorimotor rhythms to operate a brain-computer interface. Neurology 2005;64:1775-1777

93. Goldfine AM, Victor JD, Conte MM, et al. Determination of awareness in patients with severe brain injury using EEG power spectral analysis. Clin Neurophysiol 2011;22:2157-2168.

94. Giacino JT, Schnakers C, Rodriguez-Moreno D, et al. Behaviora assessment in patients with disorders of consciousness: gold standard or fool's gold? Prog Brain Res 2009:177:33-48.

95. Fins JJ, Schiff ND. In the blink of the mind's eye. Hastings Cent Rep 2010;40:21-23.

96. Owen AM, Coleman MR, Menon DK, et al. Using a hierarchical approach to investigate residual auditory cognition in persistent vegetative state. Prog Brain Res 2005;150:457-471.

97. Kane NM, Butler SR, Simpson T. Coma outcome prediction using event-related potentials: $\mathrm{P}(3)$ and mismatch negativity. Audio Neurootol 2000:5:186-191.

98. Coleman MR, Bekinschtein T, Monti MM, et al. A multimoda approach to the assessment of patients with disorders of consciousness. Prog Brain Res 2009;177:231-248. 